\title{
Practice Teaching Reform of Application Technology oriented University
}

\author{
Ke Chao Wang ${ }^{1, a^{*}}$, Tian Tian Wang ${ }^{2, b}$, Xiang Min Ren ${ }^{1, \mathrm{c}}$ and Jia Zongfu ${ }^{1, \mathrm{~d}}$ \\ ${ }^{1}$ School of Software, Harbin University, Harbin 150086, China
${ }^{2}$ School of Computer Science and Technology, Harbin Institute of Technology, Harbin 150001, China
aerickcwang@126.com, bsweetwtt@126.com, min0070@sina.com, ${ }^{\mathrm{d}}$ sjjzf@hrbu.edu.cn

Keywords: practice teaching; application technology oriented university; practice teaching system; practice ability; practical course assessment and evaluation system

\begin{abstract}
Nowadays a series of issues in the practice teaching exist, such as the lack of systematic practice teaching system especially tightly integrated with engineering application, neglect of connotation construction of practice teaching curriculum, lack of objective and impartial evaluation of the practice teaching and quality monitoring system, etc. In order to solve these problems, four levels of practice teaching system with "basic experiment, comprehensive training, innovative practices and social practices" was constructed, which consists of practice objective system, content system, management system and support assurance system. Practice teaching mode and methods reform were detailed explored. An objective, reasonable, fair assessment and evaluation system of practical courses was established. The application results show that the proposed practice teaching reform helps improve students on the basis of comprehensive practical ability, innovation and entrepreneurial ability and social adaptability.
\end{abstract}

\section{Introduction}

Nowadays, the employment of college graduates has two significant characteristics. On one hand, college graduates face employment pressure; on the other hand, many companies can not find the suitable high-quality technical and skilled employee. This phenomenon is caused by a number of factors ${ }^{[1-3]}$. Above all, many college graduates cannot meet the needs of the society is one of the important reasons. Therefore, universities reform is imperative.

Currently, local governments, educational administrative departments, industries and enterprises, universities and research institutions consensus on the reform to cultivate application technology oriented personnel who can receive both systematic training in theory and certain skills ${ }^{[4-7]}$. Particularly the construction and management of practical teaching system is the key to the application technology oriented personnel cultivation.

At the moment, there still remain several questions in practice teaching reform of application technology oriented universities ${ }^{[1-10]}$ :

Lack systematic practice teaching system especially tightly integrated with engineering application. Practice teaching is still affiliated to the theory teaching. Few independent and systematic practice teaching systems exist. First of all, lack of understanding of the requirements of social and company. Second, the practice teaching is out of touch with engineering practice.

Neglect of practice teaching curriculum connotation construction, teaching contents are outdated and teaching methods are simple.

Lack of an objective and impartial evaluation of the practice teaching and quality monitoring system.

In order to solve the above issues and cultivate students' engineering practice, innovation and professionalism, this paper constructs an application technology oriented university practice 
teaching system, researches on the practice curriculum reform in detail, and discusses the practice teachers cultivation and practice teaching quality evaluation.

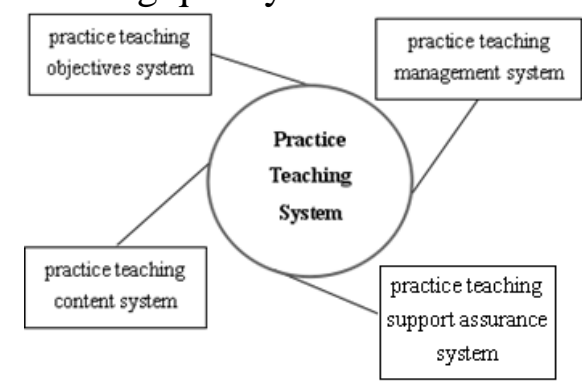

Figure. 1 Practice teaching system

\section{Constructing Application Technology oriented Practice Teaching System}

The practice teaching system is shown in Fig.1. It aims at improving students' ability of engineering practice, innovation and professional quality. It includes the following aspects.

Establishing clear practice teaching objectives system based on the engineering capability training through a combination of theory and practice of teaching. This can achieve the cultivation of students' basic ability, professional theoretical ability, professional application capabilities, innovation and R \& D capabilities.

Integrating practice teaching content system to provide multi-level step by step training based on professional training objectives. The practice teaching system consists of four levels i.e. basic experiment, comprehensive training, innovative practices and social practices. It accomplishes the combinations of inside and outside of the classroom, school and enterprise, engineering education a0nd the innovation cultivation. So that it can improve students' basic practice, comprehensive practice, innovation and entrepreneurial, social adaptability.

Construction of the practice teaching management system. Practice teaching management system reform mainly involves teaching organization, regulations administration and personnel management, so as to combine the inside and outside school teaching practice. Practice teaching institution is established dominated by practice learning and university-industry cooperation.

Establishment of practice teaching support assurance system, which mainly involves:

- Introducing and training application technology oriented practice teaching faculty to enhance practice instruction ability, especially industry experts.

- Strengthening the construction of campus practice teaching centre to provide favorable conditions for the practice teaching.

- Building technological innovation platform to promote cultivation of innovative talents;

- Building quality development platform to promote students' comprehensive quality improvement.

\section{Reform of practice teaching mode and teaching methods}

The practice teaching mode and methods have been reformed. It aims at making the practice teaching focus on capacity, emphasizing practice, encouraging innovation, and closely integrated with engineering practice. The measures taken are as follows:

Reforming the practice teaching content according to the knowledge, ability and quality of engineers, so as to unify the teaching content and the training objective. Strengthen the connotation construction of application technology oriented undergraduate courses. Then explore the three-combination training mode of "inside and outside of the classroom, school and enterprise, 
engineering education and the innovation cultivation". Eliminate the phenomenon of artificially setting the boundaries of training and practice session, according to curriculum and specialty differences. Integrate the internal structure of the practice teaching system, while recognizing the relative independence of the various professional courses at the same time, and pay more attention to reflect the intrinsic link between the different courses and professional system.

Establishing lamination progressive practice teaching mode. Increase the proportion of design and innovative experiments and build various experimentation \& practice platforms to enrich students' innovative practices inside and outside class. Set four-level skills \& quality training programs, i.e. the basic operations, professional comprehensive, integrated engineering and engineering qualities. Arrange pilot project and set the test requirements according to different categories and levels. Guide students to complete the design of the pilot program progressively to cultivate students' comprehensive ability of solving practical problems.

Creating large-scale comprehensive practice week based on school enterprise cooperation. Make practice teaching in close connection with the actual production, to accomplish the objective of learning by doing, and learning to do.

Reforming practice teaching method with full use of current information, networking and open environment. Build open network teaching platform based on advanced computer \& network technology, and realize ubiquitous teaching and learning style. School laboratory is public to students in extracurricular time, self-test style science and technology practice extracurricular activities are encouraged, which can effectively develop students' practical skills and innovation ability.

\section{Establishment of practice course assessment and evaluation system}

An objective, reasonable, fair practice course assessment and quality evaluation system is established, which focuses on appraisal students' engineering practice ability, design and innovation ability. Measures taken are as follows:

Developing practical teaching management practices and quality standards.

Using multi-dimensional appraisal methods.

Rationalizing the mechanisms of quality monitoring information collection and feedback.

Improving the quality monitoring incentives.

Highlighting the quality evaluation \& assessment of students' engineering ability, design ability and innovation ability in practice.

Adopting various evaluation methods such as comprehensive assessment and specialty evaluation, teacher evaluation +student evaluation + social evaluation, to guide teachers change focus on training effect from training accomplishments, and to guide students focus on training process from examination results. This helps in improving students' creative ability and engineering practice ability.

\section{Application and analysis}

The practice teaching reform has applied in Harbin University for three sessions. Applications results are as follows: First, a substantial increase in employment rate and quality of employment; Second, the feedback from the previous employer shows that our graduates has improved significantly in engineering practice ability and innovation ability; Third, most students are satisfied with their improvement in strong social adaptability, professional satisfaction. 


\section{Conclusion}

This paper proposed a practice teaching system, which is divided into four levels of "basic experiment, comprehensive training, innovative practices and social practices". It focuses on the combinations of "inside and outside of the classroom, school and enterprise, engineering education and the innovation cultivation", so as to fully cultivates students' abilities of "basic practice, comprehensive practice, innovation and entrepreneurial, social adaptability". The paper also presented the reform ideas and programs of practice teaching, including practice teaching content arranged according to the knowledge, ability and quality of engineers; progressive practice teaching mode; deep school-enterprise cooperation making practice teaching closely integrated with actual production. Objective and impartial evaluation system of practice teaching was constructed in order to guide teachers to assess the training effect from training results and guide students from a focus on examination results to training process. As a result, it can highlight the assessment of students' engineering practice ability, design ability and innovation ability.

\section{Acknowledgement}

This research is supported by Heilongjiang Education Science Youth Special Project under Grant No. GJD1214038, Association of Higher Education under Grant No. HGJXHA1110950, and Harbin University under Grant No. XJG2014015.

\section{References}

[1] Hong L., et al. Reformation and Innovation of Practical Teaching in Application Oriented Undergraduate Courses[J]. Research and Exploration in Laboratory, 2004, 9: 002.

[2] $\mathrm{Xu} \mathrm{H}$., et al. Construction of a Practical Teaching System for Software Engineering by School-enterprise Cooperation[J]. Research and Exploration in Laboratory. 2013, 32(6):128-130

[3] Chen Z., et al. Study of “One-focus-Two-supporting” Practical Teaching System of Cultivating Software Engineering Talents [J]. Research in Higher Education of Engineering. 2013, 5:173-175

[4] Zhong X., et al. Research on Practice Teaching Mode of Software Engineering Major Based on Collaborative Innovation[J]. Research and Exploration in Laboratory 2014, 33(4):175-179

[5] Loyalka P., et al. Factors affecting the quality of engineering education in the four largest emerging economies[J]. Higher Education, 2014: 1-28.

[6] Wen J., et al. The Construction of Gradual Engineering Practice Teaching System[J]. Research in Higher Education of Engineering. 2014, 1:159-162

[7] Li D., et al. To Cultivate Engineering Leadership of Excellent Undergraduate Students in HIT-NPSS[M]//Software Engineering Education for a Global E-Service Economy. Springer International Publishing, 2014: 119-124.

[8] Lee V., et al. From theory to practice: Teaching management using films through deductive and inductive processes[J]. The International Journal of Management Education, 2014, 12(1): 44-54.

[9] Sun H, Li X. Research on practical teaching system of the Internet of things technologies and application[C]//2014 International Conference on Education, Management and Computing Technology (ICEMCT-14). Atlantis Press, 2014. 
[10] Zhang Z. Constructing the practical teaching system of innovation and entrepreneurship education for engineering college students[C]//2014 9th International Conference on Computer Science \& Education (ICCSE). IEEE, 2014: 877-882. 